\title{
Experimental Study on Overburden Deformation Evolution under Mining Effect Based on Fiber Bragg Grating Sensing Technology
}

\author{
Wulin Lei $\mathbb{D}^{1,2}$ Jing Chai $\mathbb{D}^{1,3}$ Dingding Zhang, ${ }^{1,3}$ Yibo Ouyang, ${ }^{1}$ Zhe $\mathrm{Ma}^{1}{ }^{1}$ Wengang Du, ${ }^{1}$ \\ and Yongliang Liu ${ }^{1,3}$ \\ ${ }^{1}$ College of Energy Engineering, Xi'an University of Science and Technology, Xi'an 710054, China \\ ${ }^{2}$ School of Energy Engineering, Longdong University, Qingyang, Gansu 745000, China \\ ${ }^{3} X i$ 'an University of Science and Technology, Ministry of Education of the Western Mining and Mine Disaster Prevention and Control \\ of Key Laboratory, Xi'an 710054, China
}

Correspondence should be addressed to Wulin Lei; xakjdxwl@163.com and Jing Chai; chaij@xust.edu.cn

Received 20 March 2020; Revised 9 July 2020; Accepted 7 August 2020; Published 28 August 2020

Academic Editor: Romeo Bernini

Copyright (c) 2020 Wulin Lei et al. This is an open access article distributed under the Creative Commons Attribution License, which permits unrestricted use, distribution, and reproduction in any medium, provided the original work is properly cited.

In order to study the regularity of overburden deformation and mining pressure changes in the stope. Take the geological conditions of Hanglaiwan coal mine in Yushen mining area as the background, a $3000 \mathrm{~mm} \times 1340 \mathrm{~mm} \times 200 \mathrm{~mm}$ physical similar material model was established in laboratory. Eight fiber Bragg grating sensors were embedded in the model, used to monitor the movement and deformation of the overburden key stratum and the change of mining abutment pressure in real time and then to determine the influencing factors and strain transfer coefficients of the fiber grating through theoretical analysis and calibration experiments. The results show the following. (1) The changes in value, position, and shape of the strain can reflect the dynamic evolution process of bending deformation, breaking, and rotation of the key strata. When the key layer breaks for the first time, the strain curve shows a peak shape; when the key layer breaks periodically, the strain curve of the fiber grating sensor showed a plateau shape for a period of time. (2) The strain curve has a good corresponding relationship with the change in supporting pressure. When the strain curve of the fiber Bragg grating sensor was at the trough stage, the abutment pressure was at the peak stage, with the increase of sensor buried height, and the supporting pressure and the strain value had a linear relationship within the range of the advanced abutment pressure. The conclusion shows that the fiber Bragg grating sensor monitoring technology has good effect on the internal strain and key supporting pressure monitoring of the overburden in the model test; it provides new monitoring methods and means for the model tests.

\section{Introduction}

Underground coal mining activities will inevitably cause deformation, damage, and movement of the overlying strata. The movement of overburden can induce a series of disaster accidents such as rockburst, water permeability, roadway damage, surface subsidence, and gas outburst. And the deformation of mining overlying strata and its impact on mine safety and environment are the basic scientific issues of coal mining [1-3]. The stratum structure formed by the movement and deformation of mining overburden has significant rock mass mechanical characteristics such as multiscale deformation and large-scale movement. Since the internal activities of the rock mass cannot be directly observed, it is an obvious "black box" engineering structural problem [4]. The intelligentization of coal mines has become a requirement and an inevitable direction for the technological revolution and upgrading of the coal industry. Intelligent perception of overburden movement is one of the core elements of intelligent mining in coal mines, and the key technology of intelligent perception is monitoring technology [5-7]. The environment of underground coal mining engineering has the characteristics of complexity, concealment, and suddenness. Currently, there are few types of intelligent sensing sensors and single monitoring parameters used in the field of coal mining overburden migration monitoring, and most of them are traditional, conventional, mechanical, and inductive methods. These sensors are mostly based on manual 
observation, with a large amount of labor and low accuracy. They cannot achieve real-time monitoring and early warning, and they cannot live in the special geological environment such as dark and humid, limited space, serious electromagnetic interference, and gas emission, which urgently requires the emergence of a modern, information-based, intelligent overburden monitoring system fiber Bragg grating sensing overburden deformation monitoring system. Therefore, the application of fiber Bragg grating sensor monitoring technology in the detection network of mining overburden area will become a new direction of coal mine stratum formation control monitoring [8].

With the rapid development of optical fiber and optical communication technology in the 1970s, optical fiber sensing technology has been a new type of sensing technology which uses light wave as the carrier to sense and measure [9]. Fiber Bragg gratings have become one of the fastest-growing modern engineering structure monitoring and detection technologies due to their small size, high accuracy, convenient networking, integration of sensing and transmission, etc. [10]. In 1979, the optic fiber sensors were first tentatively embedded in composite materials for testing by NASA [11]. In 1989, Mendez et al. first proposed the introduction of optical fiber sensors into the field of geotechnical engineering for the health detection of concrete structure [12]. In 1992, Prohaska et al. first embedded fiber Bragg gratings into concrete structure to measure strain and introduced fiber grating sensing technology, which was originally used in the aerospace and aerospace fields into civil engineering [13]. In 1997, Meissner et al. buried Bragg gratings in a prestressed concrete bridge on the A4 highway near Dresden [14]. Through comparative tests, the application feasibility of fiber grating sensors has been confirmed. Schulz et al. embedded fiber Bragg gratings in concrete structures to test stress and strain and perform nondestructive assessment of structural integrity and internal stress-strain state detection [15-17]. Yeager et al. installed the FBG sensor on a rectangular thin plate made of composite materials by embedding and surface bonding, tested the influence of the humid environment on the optical fiber readings, and established a diagnostic method for the health damage of the composite structure [18]. Since the end of the 20th century, Chinese scholars have begun to apply FBG sensing technology to engineering practice and achieved rapid development. Hong et al. reviewed the current status of application of fiber optic sensor to civil engineering both domestic and abroad, focused on the Bragg grating strain sensor, and pointed out the perspective usage and future studies of fiber optic sensing techniques in civil engineering [19]. Aimed at the detection for structure reinforcement, Desheng put forward a kind of stickup fiber Bragg grating sensor to monitor the strain of structure during its reinforcing period, which can realize real-time and online monitoring [20]. According to the characteristics of strain, vibration, and impact of the FBG sensor, Jiang et al. reported a fiber optic intrusion alarm system using quasidistributed FBG sensors [21]. Jian-Hua et al. embedded fiber Bragg grating sensors in the dam body and dam foundation, respectively, to monitor the internal displacement of the structural model in the process of overload [22]. Zhou et al. proposed to combine the Brillouin distributed sensing technology with local high-precision optical fiber Bragg grating (FBG) technology to build an integrated system of distributed full-scale and local monitoring technique with single optical fiber [23]. Zhu et al. demonstrated the feasibility of incorporating fiber Bragg grating (FBG) sensing technology into health monitoring of foundation structures and innovated FBG strain sensors, temperature sensors, settlement sensors, and horizontal inclinometers, which have been developed to monitor strains, temperatures, and displacements in foundations [24]. Guangqing et al. discussed the key problems of package protection, temperature compensation, and monitoring system integration which were often encountered in the monitoring of FBG used in the construction of tunnels $[25,26]$. It has been indicated that the survival rate of the FBG sensor can be greatly raised via proper sealing and protection, and the real-time monitoring for the strain and stress of the arch and supporting bar and temperature of the tunnel structure during the blasting excavating and concrete spraying of the tunnel was feasible. Ni et al. installed FBG temperature, strain, and pressure sensors in underground water pipes [27]. After laboratory tests and field tests, he has successfully found abnormal and local defects in water pipe structures and established a fiber Bragg grating monitoring network for the structural integrity of underground water pipes. Liu et al. reported a fiber optic strain sensor with nanostrain resolution and large measurement range [28]. For sensing the earth crustal deformation, with this sensor, the tide-induced crustal deformation and the seismic wave were successfully recorded in field experiments. Fang e al. combined and integrated the fiber Bragg grating sensing technology with the safety production of coal mining and discussed and applied it in the aspects of roof separation, anchor cable load, goaf temperature, shearer attitude, and so on [29-31]. Chai et al. conducted a crosscombination study on fiber Bragg grating sensing technology and coal mine production safety issues and tested the mechanical properties of rocks, physical similarity simulation test, and settlement of the huge loose layer by using fiber Bragg grating sensing technology. And it has provided new ideas for solving the safety, highefficiency, and intelligent perception of basic information of coal mining [32-35]. At present, FBG sensing and monitoring technology has been widely used in civil engineering, hydraulic engineering, composite materials, medicine, electric power, aerospace, and other fields and has achieved significant research results [36-38]. However, the application of FBG sensing and monitoring technology in coal mining is short, and it is still in the initial stage of application research and development. There are still many key technologies that have not yet been resolved, especially the application of fiber Bragg grating sensing technology in monitoring the deformation of overburden. There are also some engineering application problems, such as the coupling and transfer relationship between the FBG sensor and the tested substrate, the calibration of the fiber grating sensor, and the characterization of the overburden migration law by the fiber Bragg grating sensing technology $[39,40]$.

In order to realize the precise monitoring of deformation of overburden rock by fiber Bragg grating sensing technology, 
based on the deformation mechanism of overburden rock and the principle of fiber Bragg grating sensing, a strain transfer calculation model of fiber Bragg grating packaging material overburden was established and analyzed, and the transitive relationship between the strain of the fiber Bragg grating and the strain of the overburden was analyzed. Then, the strain transfer coefficient was obtained by the calibration experiment of the FBG sensor. Combined with on-site coal mining geological conditions, a physical similar model was constructed in the laboratory, and fiber Bragg grating sensing technology was used to monitor the deformation of the overburden and the change of the supporting pressure in the process of model mining in real time and to monitor overburden bending, breaking, and delamination. Performing characterization to realize the intelligent perception of deformation of mining overburden is of great significance for promoting the informationization of coal mine production and the constructing intelligent mines.

\section{Working Principles of FBG}

In 1978, Hill et al. first used the standing wave writing method to make the first fiber Bragg grating in a germanium-doped fiber. After nearly 40 years of development, the fiber Bragg grating sensor has been widely used in the field of structural health monitoring research [41]. Fiber Bragg grating makes use of the photosensitivity of optical fiber materials, through special fabrication methods (usually irradiating the Ge magnetic core fiber with about $240 \mathrm{~nm}$ ultraviolet light), which makes the external incident photons interact with the doped particles in the fiber core, resulting in the periodic or aperiodic permanent change of the refractive index of the core along the fiber axis, forming a spatial phase grating in the core $[42,43]$. According to coupled-mode theory, when broadband light propagates in an optical fiber, the light that meets the Bragg condition will be reflected, and the remaining light will continue to propagate forward as the transmitted light, as shown in Figure 1. The Bragg wavelength can be expressed as

$$
\lambda_{\mathrm{B}}=2 n_{\mathrm{eff}} \Lambda,
$$

where $\lambda_{\mathrm{B}}$ is the center wavelength of the Bragg, $n_{\text {eff }}$ is the effective refractive index, and $\Lambda$ is the grating period.

When the temperature or stress around the fiber Bragg grating changes, it will cause the grating period and the effective refractive index of the core to change, which will cause the Bragg center wavelength to shift. It is assumed that the changes of the Bragg center wavelength caused by strain and temperature are independent of each other. For the single-mode quartz fiber, the Bragg center wavelength, strain and temperature of the sensing fiber are linearly related [44].

$$
\frac{\Delta \lambda_{\mathrm{B}}}{\lambda_{\mathrm{B}}}=K_{\varepsilon} \Delta \varepsilon+K_{T} \Delta T,
$$

where $\Delta \lambda_{\mathrm{B}}$ is the drift amount of the Bragg central wavelength, $\Delta \varepsilon$ and $\Delta T$ are the strain and temperature variation of the grating, respectively, $K_{\varepsilon}$ and $K_{T}$ are the strain and temperature calibration coefficient of the fiber Bragg grating, respectively.

In the strain measurement, in order to avoid the influence of temperature on the measurement, a ceramic-encapsulated temperature sensor is embedded as temperature compensation in the test [45], and the value of strain $\delta \varepsilon$ of FBG can be obtained by eliminating the influence of temperature change $\Delta T$. Assuming that the temperature is constant, that is, $\Delta T=0$, formula (2) can be converted to

$$
\frac{\Delta \lambda_{\mathrm{B}}}{\lambda_{\mathrm{B}}}=K_{\varepsilon} \Delta \varepsilon .
$$

From the above formula (3), it can be known that when the optical fiber is subjected to axial tensile stress, $\varepsilon$ increases, and the central wavelength of the fiber grating increases, and vice versa. And the wavelength change data can be processed into strain results.

In the actual engineering monitoring system, multiple fiber Bragg grating sensors are usually distributed on the same fiber; that is, several fiber Bragg grating sensors can use topology or sensor array to build a sensor network system that meets the needs of various levels or develop a quasidistributed solution so as to achieve a large area, wide coverage, and multidimensional real-time intelligent monitoring. When multiple fiber gratings are connected in series to form a sensing array for quasidistribution monitoring, in order to enable the demodulation system to obtain the wavelength information of each reflection center, it is necessary to ensure that each fiber grating can be "searched." And it is required that the central wavelength and its variation range of each FBG in the array cannot overlap, cross, or disturb each other. In the fiber grating quasidistribution sensing array, the center wavelengths of two adjacent fiber gratings need to have a certain interval, and the two adjacent fiber grating sensing signals must not crosstalk with each other $[46,47]$.

$$
\lambda_{i}+\Delta \lambda_{i+}<\lambda_{j}-\Delta \lambda_{j+}(1 \leq i \leq j)
$$

In the formula, set $i=j-1, i$ and $j$ are two adjacent FBG sensors in the array, $\lambda_{i}$ and $\lambda_{j}$ are the center wavelengths of any two adjacent gratings, $\Delta \lambda_{i+}$ and $\Delta \lambda_{j+}$ are the maximum positive wavelength shifts, and $\Delta \lambda_{i-}$ and $\Delta \lambda_{j-}$ are the maximum negative wavelength shifts.

Therefore, when using the grating string for testing, the grating wavelength parameters must be set to meet its fluctuation range.

\section{Strain Transfer Theory of the FBG Sensor}

The fiber grating sensor's mechanical transfer interface effect with the deformation of the packaging material and the substrate during the strain transfer process causes the strain of the fiber grating to be different from the actual strain of the measured matrix. Therefore, it is necessary to study the mechanical state of FBG embedded in the measured matrix and the interface transfer characteristics of strain sensing $[48,49]$. The strain transfer model of the FBG sensor is 


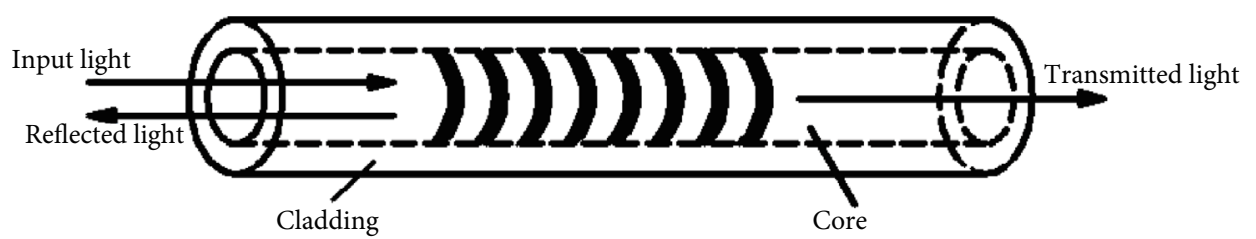

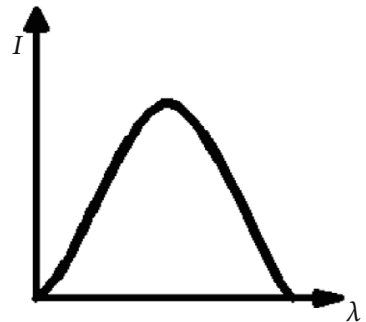

Input spectrum

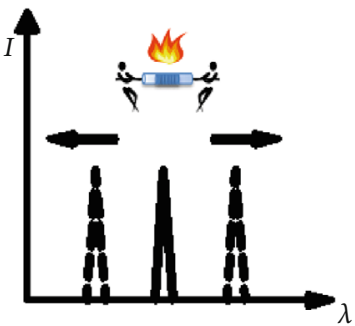

Reflected spectrum

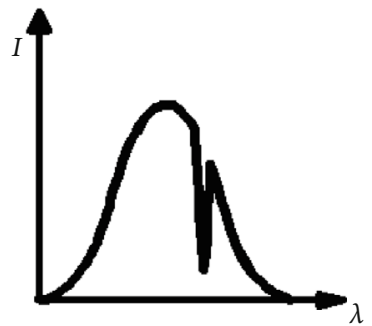

Transmitted spectrum

FIgURE 1: Sensing principle of fiber Bragg grating.

established as shown in Figure 2. With the center position of the FBG sensor as the coordinate origin, the fiber axis is set as the $x$ coordinate axis, and the vertical drilling direction is the $y$ coordinate axis. The following assumptions are made: (1) the materials are linear, and the matrix material only bears uniform tensile strain along the fiber axis direction, not directly affected by external force; (2) the FBG sensor is completely coupled with the packaging material and the measured matrix, without slippage.

The mechanical equilibrium condition of the fiber grating sensor's axial resultant force is zero, and we get

$$
d \sigma_{q}=-\frac{2 \tau_{q}\left(x, r_{q}\right)}{r_{q}}
$$

In the formula, $\sigma_{q}$ is the axial stress of the FBG sensor, $\tau_{q}$ is the shear force along the surface of the FBG sensor, $r_{q}$ is the half width of the FBG sensor, $L$ is the half gauge length of an optical iffier sensor, and $2 L$ is the total length that the fiber is bonded to the host material through the middle layer.

For the packaging material of the FBG sensor, if the resultant force of any cross section in the axial direction is zero, it can be obtained from equation (5).

$$
\tau_{c}(x, r)=-\frac{r_{q}^{2}}{2 r} \frac{d \sigma_{q}}{d x}-\frac{r^{2}-r_{q}^{2}}{2 r} \frac{d \sigma_{c}}{d x},
$$

where $\tau_{c}$ is the shear stress on the surface of the packaging material of the FBG sensor, and $\sigma_{c}$ is the axial stress of the packaging material of the FBG sensor.

Assuming that the stress gradients of each layer of the fiber Bragg grating sensor are equal, formula (7) can be obtained by neglecting the Poisson effect.

$$
\tau_{c}(x, r)=-\left(\frac{r_{q}^{2}}{2 r} E_{q}+\frac{r^{2}-r_{q}^{2}}{2 r} E_{c}\right) \frac{d \varepsilon_{q}}{d x} .
$$

In the formula, $E_{c}$ is Young's modulus of the coating or adhesive, $E_{q}$ is Young's modulus of the fiber, and $\varepsilon_{q}$ is the axial stress.

If only the axial deformation is considered, $\mu$ is the shear displacement of the packaging material along the axis of the fiber Bragg grating sensor, and formula (8) can be obtained.

$$
\tau_{c}(x, r)=G_{c} \frac{d \mu}{d r}
$$

where $G_{c}$ is the shear modulus of the fiber Bragg grating sensor packaging material (GPa).

Combining formulas (7) and (8), we get

$\mu_{c}-\mu_{q}=-\left(1+\mu_{c}\right)\left[\frac{1}{2} r_{c}^{2}-\frac{1}{2} r_{q}^{2}-\left(1-\frac{E_{q}}{E_{c}}\right) r_{q}^{2} \ln \left(\frac{r_{c}}{r_{q}}\right)\right] \frac{d \varepsilon_{q}}{d x}$.

In the formula, $r_{c}$ is the half width of the tested matrix, $r_{q}$ is the half width of the FBG sensor, and $\mu_{c}$ and $\mu_{q}$, respectively, denote the axial displacement from the $x$ coordinate origin in the host material and fiber.

Let $k$ be the strain lag parameter.

$k_{2}^{2}=\frac{1}{\left(1+\mu_{c}\right)\left[(1 / 2) r_{c}^{2}-(1 / 2) r_{q}^{2}-\left(1-\left(E_{q} / E_{c}\right)\right) r_{q}^{2} \ln \left(r_{c} / r_{q}\right)\right]}$.

By deriving equation (9), the strain transfer rate of the FBG sensor in the measured substrate can be obtained.

$$
\alpha_{2}\left(k_{2}, x\right)=1-\frac{\cosh \left(k_{2} x\right)}{\cosh \left(k_{2} L\right)} .
$$

It can be known from the above formula that the factors affecting the strain transfer rate are the half-length of the 


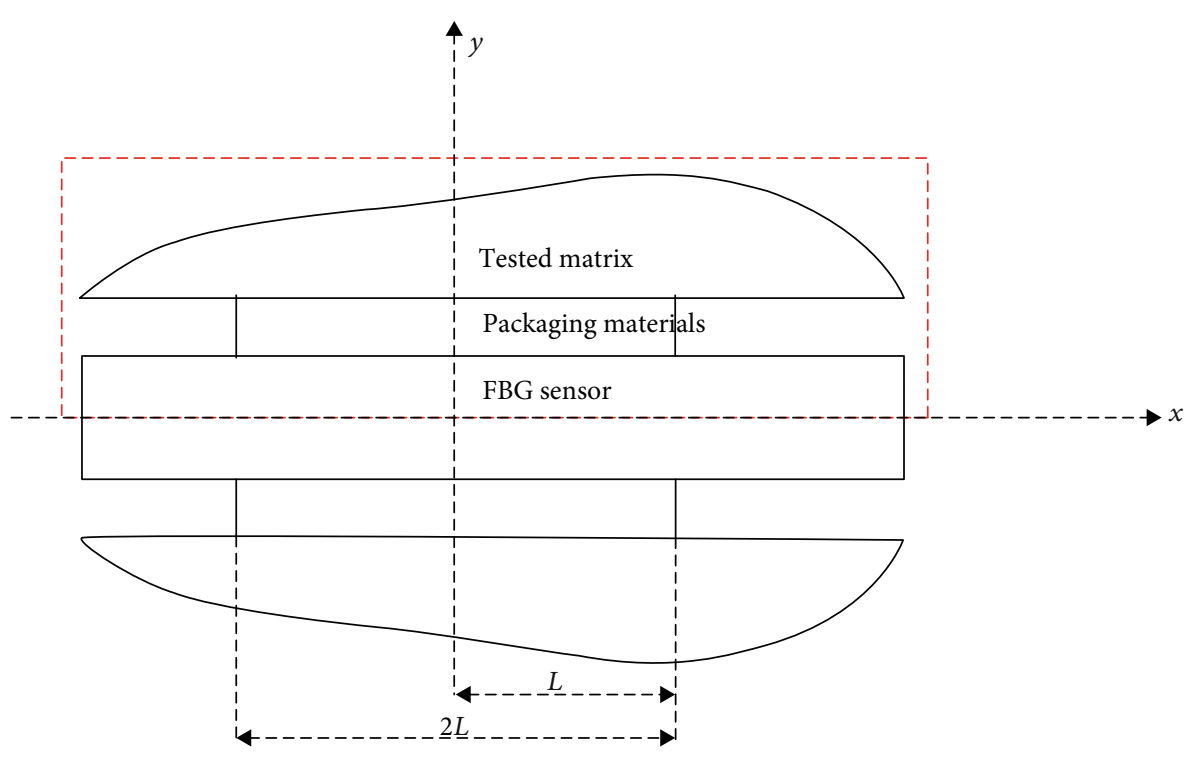

(a) Optical fiber of gauge length $2 L$

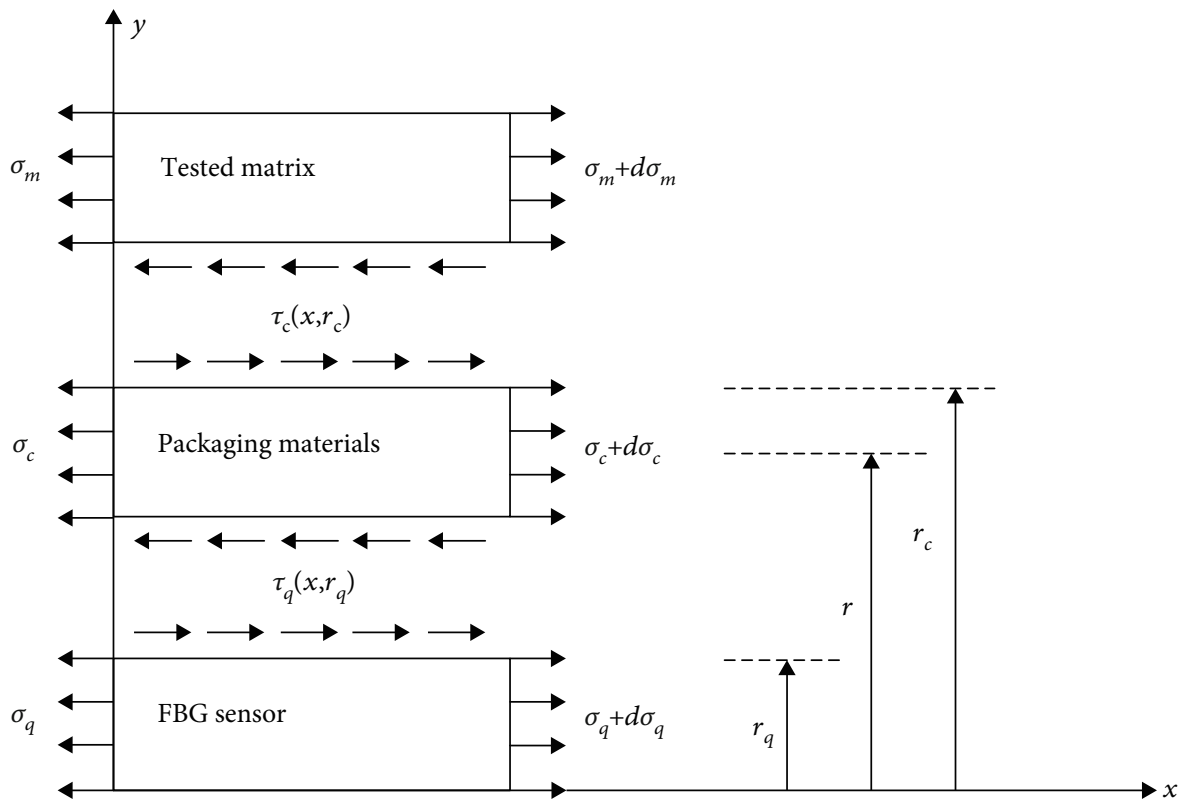

(b) Strain transfer analysis of the FBG sensor

Figure 2: Coordinate system of symmetrical section of optical fiber.

sensor, the elastic modulus of the packaging material, and Poisson's ratio.

\section{Calibration Experiment of the FBG Sensor}

The FBG sensor is calibrated by equal strength beam experiment. The experimental materials are $1 \mathrm{~m}$ equal strength beam of Beijing Runhengao Company, M1 weight of Shanghai Shirun Industrial Co., Ltd., red optical fiber pen of Zhejiang Yousi Company, Sm225 fiber grating network demodulator of MOI Company in Germany, CM-1L static resistance strain analyzer of GUMI company in the USA, BX120-100AA resistance strain gauge of Beijing Xizhou Company, AV6481 series welding machine of the 41st
Research Institute of China Electronics Technology Group Corporation, BLE company $50 \mathrm{ml}$ epoxy resin, OJE company $75 \%$ alcohol, etc. The main accessories of the equal strength beam test device are equal strength beam, base, weight hook, and adjusting leg. The equal strength beam is $45 \#$ low carbon steel, the elastic modulus is about $210 \mathrm{GPa} / \mathrm{m}^{2}$, Poisson's ratio is about 0.28 , the overall dimension is $1100 \mathrm{~mm}$ (length) $\times$ $315 \mathrm{~mm}$ (width) $\times 310 \mathrm{~mm}$ (height), the ambient temperature is $0 \sim 40^{\circ} \mathrm{C}$, and the relative humidity is less than $65 \%$. The calibration test system diagram is shown in Figure 3. The test strain gauge and FBG were, respectively, pasted on the surface of equal strength beam with epoxy resin adhesive and evenly arranged. The fiber Bragg grating sensor and fiber jumper are fused into a fiber by using the fusion stage, then connected 


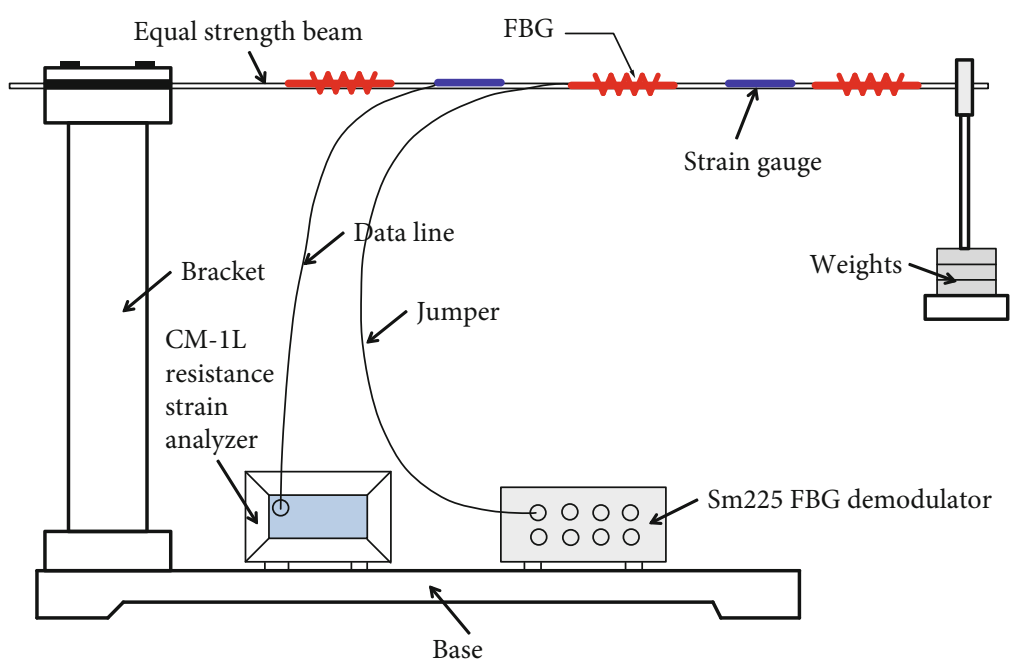

FIGURE 3: FBG sensor calibration system.

Table 1: Wavelength drift of the FBG sensor.

\begin{tabular}{lccccc}
\hline $\begin{array}{l}\text { Sensor } \\
\text { number }\end{array}$ & $\begin{array}{c}\text { Before } \\
\text { loading } \\
(\mathrm{pm})\end{array}$ & $\begin{array}{c}\text { 1st level } \\
\text { loading } \\
(\mathrm{pm})\end{array}$ & $\begin{array}{c}\text { 2nd level } \\
\text { loading } \\
(\mathrm{pm})\end{array}$ & $\begin{array}{c}\text { 3rd level } \\
\text { loading } \\
(\mathrm{pm})\end{array}$ & $\begin{array}{c}\text { 4th level } \\
\text { loading } \\
(\mathrm{pm})\end{array}$ \\
\hline FBG1 & 0 & 95.1 & 189.63 & 285.85 & 373.5 \\
FBG2 & 0 & 97.61 & 193.58 & 289.86 & 381.61 \\
FBG3 & 0 & 97.79 & 196.36 & 293.79 & 386.08 \\
\hline
\end{tabular}

to the FBG network demodulator, and then connected to the resistance strain analyzer by the strain gauge connecting wire.

The calibration test was carried out in a step-by-step loading mode, with the load of $5 \mathrm{~N}$ for each step. After loading, the data would be collected once after the equal strength beam stabilizes. This calibration experiment was loaded with a total of four stages to $20 \mathrm{~N}$, and the test loading was over. The wavelength drift of the collected FBG sensors under different loads is shown in Table 1. During the four-stage loading, the average strain values of the resistance strain gauge were $81.82 \mu \varepsilon, 163.25 \mu \varepsilon, 244.91 \mu \varepsilon$, and $321.44 \mu \varepsilon$, respectively. The average wavelength shift of the corresponding FBG sensors were $96.83 \mathrm{pm}, 193.19 \mathrm{pm}, 289.83 \mathrm{pm}$, and $380.40 \mathrm{pm}$, respectively. From Figure 4, the strain transfer coefficient of the FBG sensor is $1.18 \mathrm{pm} / \mu \varepsilon$.

The change rule and fitting curve of the strain value of the FBG sensor under the fourth level load are shown in Figure 5. It can be seen from Figure 5 that the strain value measured by FBG has an excellent linear relationship with the load.

\section{FBG Sensing Monitoring Test of Overburden Deformation}

5.1. Establishment of the Physical Similarity Model. The model test takes the comprehensive mining face of Hanglaiwan Coal Mine as the research object. The average thickness of the coal seam is about $9.13 \mathrm{~m}$, the average dip angle is about $0.5^{\circ}$, the average burial depth is about $230 \mathrm{~m}$, the average thickness of bedrock is about $150 \mathrm{~m}$, and the average of the loose layer is about $80 \mathrm{~m}$. The coal seam contains 1 to 2 layers of mudstone and lime mudstone, with a thickness of 0.05 to $0.46 \mathrm{~m}$, which belongs to the type of simple structure. The direct roof is dominated by siltstone and mudstone, with a small amount of fine-coarse feldspar sandstone. The direct floor is mainly composed of siltstone and mudstone, with a small amount of fine-coarse sandstone and carbonaceous mudstone; the specific lithologic parameters of the formation are shown in Table 2. Based on the mining geological conditions of the fully mechanized coal mining face in Hanglaiwan Coal Mine as a prototype, a plane stress model with a length $\times$ width $\times$ height of $3000 \mathrm{~mm} \times 200 \mathrm{~mm} \times 1150 \mathrm{~mm}$ is established according to the test prototype geological conditions and test purposes. According to the similarity theory, the model test must be similar to the original system in geometry, kinematics, and dynamics. Therefore, similar parameters such as the geometric similarity ratio and bulk density similarity ratio are determined as shown in Table 3. In this experiment, river sand, fly ash, and clay were used as aggregate, gypsum, and large white powder (calcium carbonate) as cementing material, mica powder as layered material, and water as mixture. The river sand is divided into single size particles with diameters of $0.18-0.78 \mathrm{~mm}$ by standard sand and stone square hole sieve, and their average diameters are $0.31-0.52 \mathrm{~mm}$. The setting time of gypsum is more than $3 \mathrm{~min}$, the compressive strength is more than 4.0 $\mathrm{MPa}$, the flexural strength is more than 2.0 MPa, and the fineness of the residue of the $0.2 \mathrm{~mm}$ square hole sieve is less than $10 \%$. The specification of white powder is 300 mesh. The particle size of mica powder is $800 \mathrm{mesh}$, the sand content is $0.05 \%$, and the loose density is $0.38 \mathrm{~g} / \mathrm{cm}^{3}$. According to the proportion number of each simulated rock stratum, mix the materials with water and put them into the model frame.

5.2. FBG Monitoring System. A total of 9 fiber Bragg grating sensors are installed in the physical model. The FBG sensors were the same batch and the same type of sensor as those used in the calibration experiment, and the set number is 


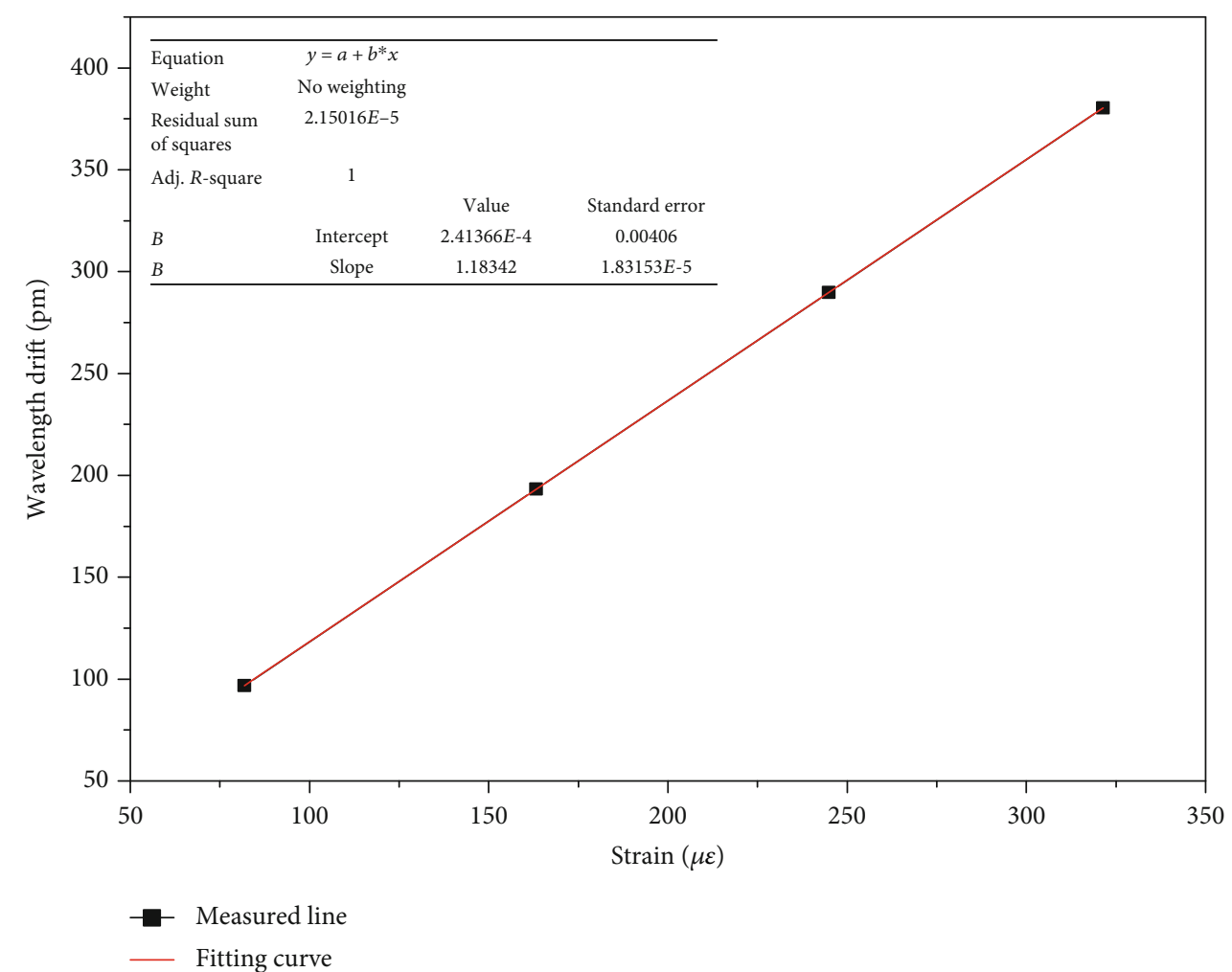

FIGURE 4: Fitting curve of FBG sensor calibration data.

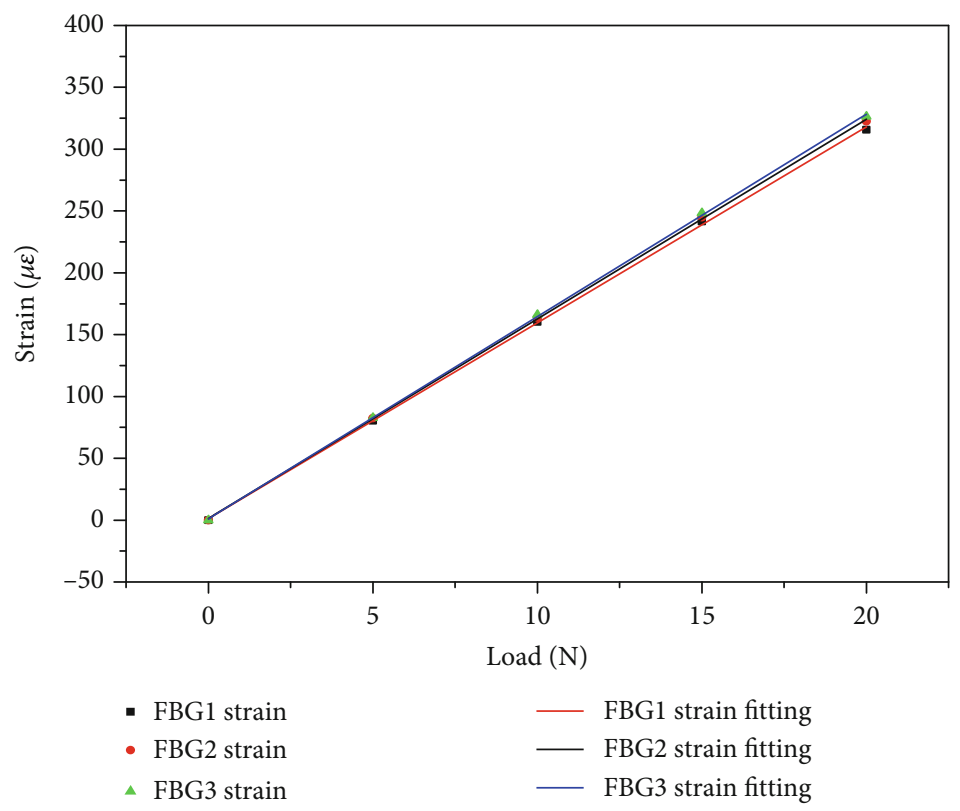

FIGURE 5: Fitting curve of FBG monitoring strain data.

FBG001 FBG009. In the similar model, the FBG sensor is embedded in advance, and they are buried vertically. In the physical model, the FBG1 and FBG2 sensors were buried in the rock stratum (the subcritical stratum) $500 \mathrm{~mm}$ away from the coal seam floor, and the FBG3 and FBG4 sensors were buried in the rock stratum (the subcritical stratum) $700 \mathrm{~mm}$ away from the coal seam floor. Those sensors were used to monitor the mining deformation movement rules of different heights, different horizons, and different lithology. In addition, the FBG5, FBG6, FBG7, and FBG8 sensors were buried in the rock stratum $250 \mathrm{~mm}$ away from the coal seam floor in the model to monitor the distribution rule of supporting pressure in the stope. The FBG sensors of the same height in the model were connected in series, and the FBG 
TABLE 2: Main overburden stratum structure and physical parameters.

\begin{tabular}{lcccc}
\hline Strata & Compressive strength $(\mathrm{MPa})$ & Tensile strength $(\mathrm{MPa})$ & Elastic modulus $(\mathrm{GPa})$ & Poisson's ratio \\
\hline Aeolian sand & 11.6 & 0.23 & 12.0 & 20.4 \\
Loess & 15.3 & 0.29 & 23.5 & 0.30 \\
Mudstone & 20.5 & 0.12 & 26.0 & 0.31 \\
Sandy mudstone & 32.1 & 3.21 & 33.9 & 0.34 \\
Medium sandstone & 40.6 & 5.59 & 32.5 & 0.30 \\
Fine sandstone & 46.6 & 5.00 & 36.0 & 0.29 \\
Siltstone & 41.9 & 2.03 & 13.5 & 0.32 \\
Coal seam & 16.2 & 0.86 & 0.27 \\
\hline
\end{tabular}

TABLE 3: Main similar parameters.

\begin{tabular}{lc}
\hline Name & Parameter \\
\hline Geometric similarity ratio & $1: 200$ \\
Bulk density similarity ratio & $1: 1.6$ \\
Stress similarity ratio & $1: 320$ \\
Displacement similarity ratio & $1: 200$ \\
Time similarity ratio & $1: 14$ \\
\hline
\end{tabular}

demodulator was connected after the jumper was fused. The whole monitoring system of this test consists of the Sm225 FBG network demodulator, computer, and FBG sensor, as shown in Figure 6.

5.3. Model Test Process. The total length of the physical model is $3000 \mathrm{~mm}$, the boundary coal pillars of $300 \mathrm{~mm}$ are set on both sides of the model, and the mining length of the model is $2400 \mathrm{~mm}$. The mining length of the model is $20 \mathrm{~mm}$ each time, 20 times a day, and the total mining length is $400 \mathrm{~mm}$ per day; the actual picture of model mining is shown in Figure 7. It took 6 days for the experimenter to complete the mining of the whole physical model. After each model mining, the experimenter first recorded the model excavation time, distance, and other information. After the deformation of overburden was stable, the sensing data of FBG could be collected. Then, the model test entered the next model mining cycle, and it would not be completed until $2400 \mathrm{~mm}$ was mined. The entire model test must observe and record the whole process of the movement and deformation of the mining overburden in detail.

\section{Analysis of FBG Sensor Monitoring Data}

6.1. Monitoring the Movement and Deformation of Overburden by the FBG Sensor. The FBG1 sensor is located in the subcritical stratum above the coal seam of the fully mechanized mining face, which is away from $500 \mathrm{~mm}$ in front of the working face. The monitoring data curve of the FBG1 sensor is shown in Figure 8. After mining along the strike direction of the working face for a certain distance, because the FBG1 sensor was far away from the coal seam and was not affected by mining, the strain curve of the FBG1 sensor data had not changed significantly in the early stage of mining. When the working face advanced to
$480 \mathrm{~mm}$ (point B in Figure 8), the strain value of the FBG1 sensor has changed significantly, and the strain value has increased from $0 \mu \varepsilon$ to $5.71 \mu \varepsilon$, indicating that the subcritical stratum had begun to be affected by coal mining. When the working face continued to advance to $720 \mathrm{~mm}$ (point $\mathrm{C}$ in Figure 8), the overburden had collapsed below the subcritical stratum, and the subcritical stratum had formed a fixed beam structure at both ends. Under the action of the overburden load, the subcritical stratum had bent and deformed, and the strain value had increased rapidly to $40.61 \mu \varepsilon$. When the working face continued to advance to $780 \mathrm{~mm}$ (point D in Figure 8), the first collapse of the subcritical stratum occurred, and the strain value of the FBG1 sensor was affected by the collapse, and the strain value decreased sharply to $96.92 \mu \varepsilon$, which was negative at this time. When the working face continued to advance to $2200 \mathrm{~mm}$ (point $\mathrm{E}$ in Figure 8), the rock mass of the key stratum where the FBG1 sensor was located collapsed into the goaf. Since the FBG1 sensor was only affected by the gravity of the caving rock mass in the goaf, the strain value did not change significantly and trended in a steady state. The strain value curve of the FBG1 sensor reflects the first breaking process of the subcritical stratum and had the characteristics of short and rapid movement time.

The FBG2 sensor is located in the subcritical stratum above the coal seam of the fully mechanized mining face, which is away from $900 \mathrm{~mm}$ in front of the working face. The monitoring data curve of the FBG2 sensor is shown in Figure 9. In the early stage of mining, because the rock formation where the FBG2 sensor was embedded was far from the working face, the monitoring data of the FBG2 sensor was not affected by coal mining. When the working face advanced to $840 \mathrm{~mm}$ (point B in Figure 9), the strain value of the FBG2 sensor began to change significantly. The strain value is $-5.98 \mu \varepsilon$, which is negative. The FBG2 sensor was subjected to compressive strain, indicating that the FBG2 sensor was in the leading support pressure area of the working face. When the working face continued to advance to $1040 \mathrm{~mm}$ (point C in Figure 9), the subcritical stratum where the FBG2 sensor was affected by coal mining moved and deformed to form a cantilever beam structure, and the strain value increased sharply to $2145.18 \mu \varepsilon$, reaching the maximum peak. When the working face continued to advance to $1360 \mathrm{~mm}$ (point D in Figure 9), the subcritical stratum where the FBG2 sensor is located reached the bearing limit, periodic 


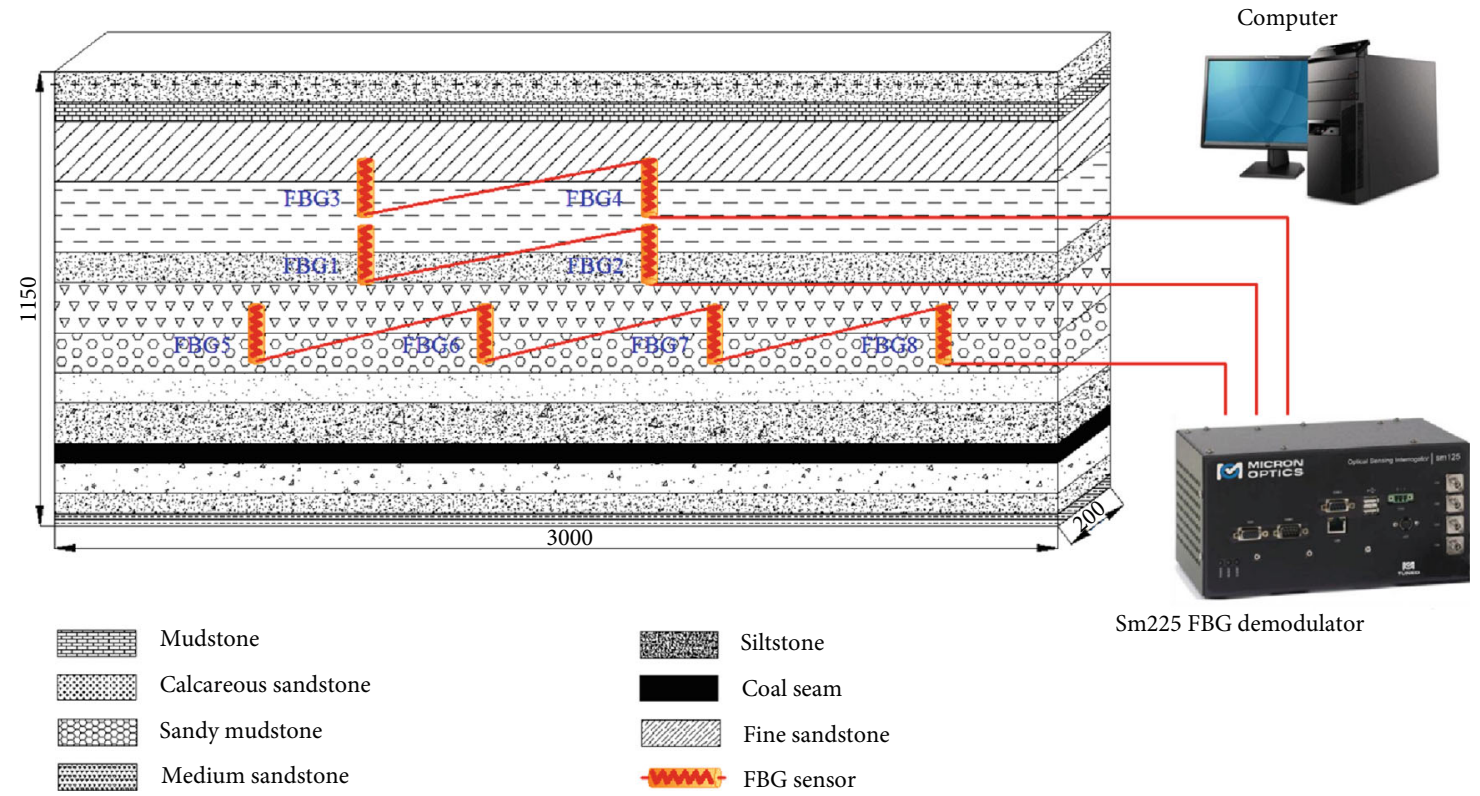

FIGURE 6: FBG sensor monitoring system.

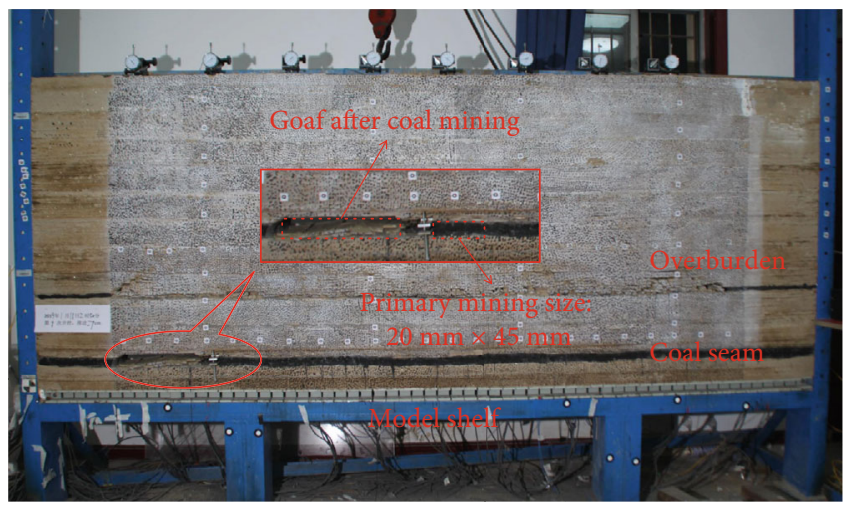

Figure 7: Physical drawing of model mining.

breakage occurred, and the rock block broke and touched the gangue and is hinged with the rear rock block to form a masonry beam structure. At this time, the strain value of the FBG2 sensor decreased sharply to $883.39 \mu \varepsilon$. When the working face continued to advance to $2200 \mathrm{~mm}$ (point $\mathrm{E}$ in Figure 9), the strain value of the FBG2 sensor was basically stabilized. It was shown that the strain curve of the FBG2 sensor reflected the process of periodic fracture of the subcritical stratum with a time duration, which was in sharp contrast to the abruptness of the first fracture.

The FBG3 sensor is located in the main key stratum above the coal seam and $500 \mathrm{~mm}$ in front of the fully mechanized mining face. The monitoring data curve of the FBG3 sensor is shown in Figure 10. When the working face advanced to $600 \mathrm{~mm}$ (point B in Figure 10), because the FBG3 sensor was located far from the coal seam, it was not affected by coal mining. When the working face advanced to $1000 \mathrm{~mm}$ (point $C$ in Figure 10), there was a large separation layer under the key stratum where the FBG3 sensor is located, and the main key stratum began to bend and deform slightly under its influence. The strain value of the FBG3 sensor started to increase gradually and increased to a peak of $60.99 \mu \varepsilon$. When the working face continued to advance to $1120 \mathrm{~mm}$ (point D in Figure 10), the main key stratum broke for the first time, but it is not unstable. Because the goaf was basically filled, the rotational deformation space of the rock block is limited. The rock block implanted by the FBG3 sensor forms a good hinged structure with the rear rock block and still has a certain bearing capacity; the strain value of the FBG3 sensor is reduced to $43.34 \mu \varepsilon$. When the working face continued to advance to $2200 \mathrm{~mm}$ (point $\mathrm{E}$ in Figure 10), due to the limited rotation space, the deformation of the rock block where the FBG3 sensor was located was small, and the strain value basically tended to be stable. The strain curve of the monitoring data of the FBG3 sensor reflects that the initial breaking process of the main key stratum also had the characteristics of short and rapid movement time, but due to the limitation of the deformation space of the rock layer, the main key stratum is broken for the first time but not unstable, and the deformation is small.

The FBG4 sensor was located in the main key layer above the coal seam and $900 \mathrm{~mm}$ in front of the fully mechanized mining face. The monitoring data curve of the FBG4 sensor is shown in Figure 11. When the fully mechanized mining face advanced from $0 \mathrm{~mm}$ to $1000 \mathrm{~mm}$ (section $\mathrm{AB}$ in Figure 11), the strain value of the FBG4 sensor decreased from $0 \mu \varepsilon$ to $-42.78 \mu \varepsilon$ and then increased from $42.78 \mu \varepsilon$ to $12.13 \mu \varepsilon$, indicating that the rock blocks monitored by the FBG4 sensor had an interactive state of tensile and compressive stress occurs in the process of pushing the block in the working face. When the fully mechanized mining face continued to advance to $1360 \mathrm{~mm}$ (point $\mathrm{C}$ in Figure 11), the rock block of the main key stratum where the FBG4 sensor was located formed a cantilever beam structure. As the coal mining was subjected to the 


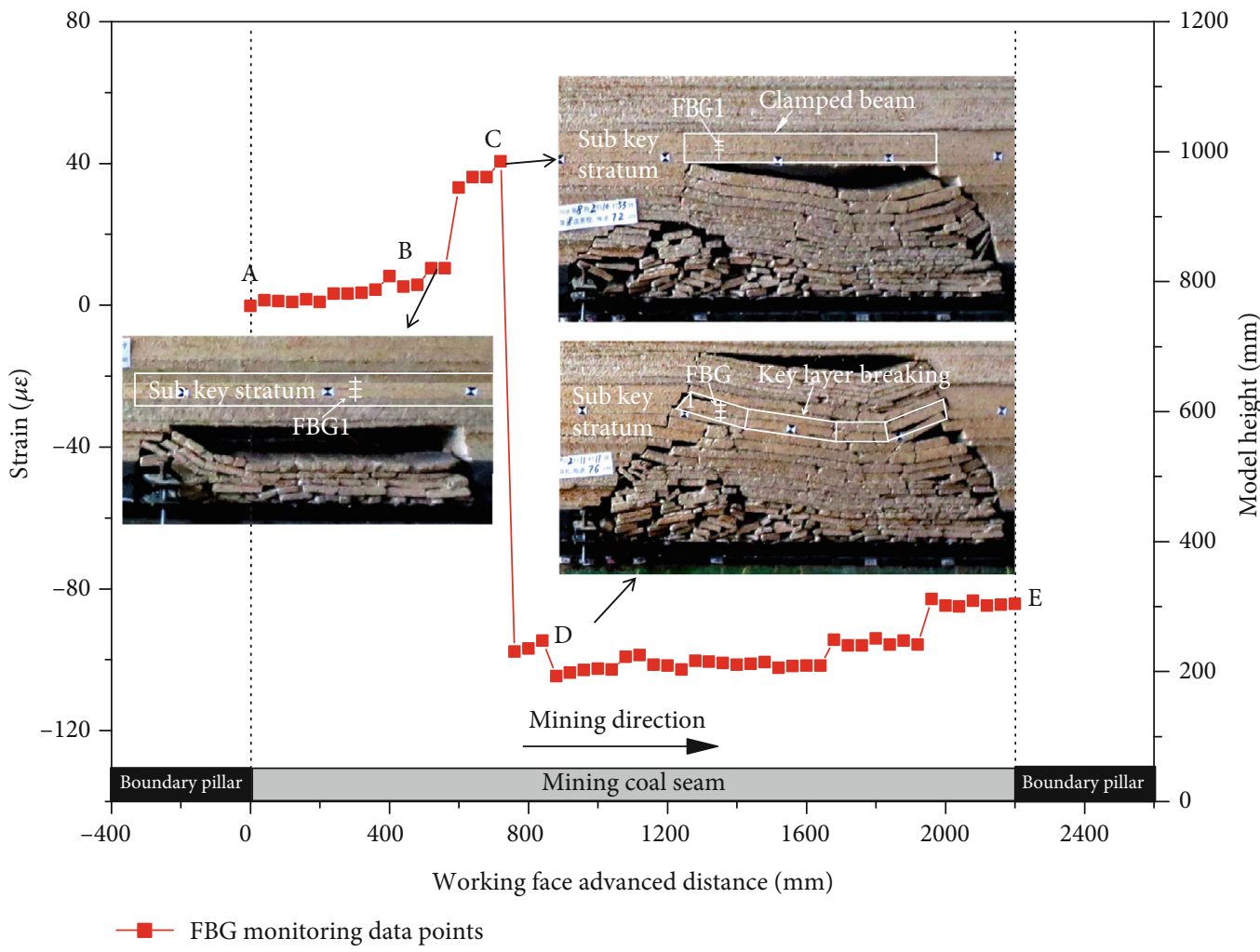

FIGURE 8: Strain monitoring curve of the subcritical stratum (FBG1).

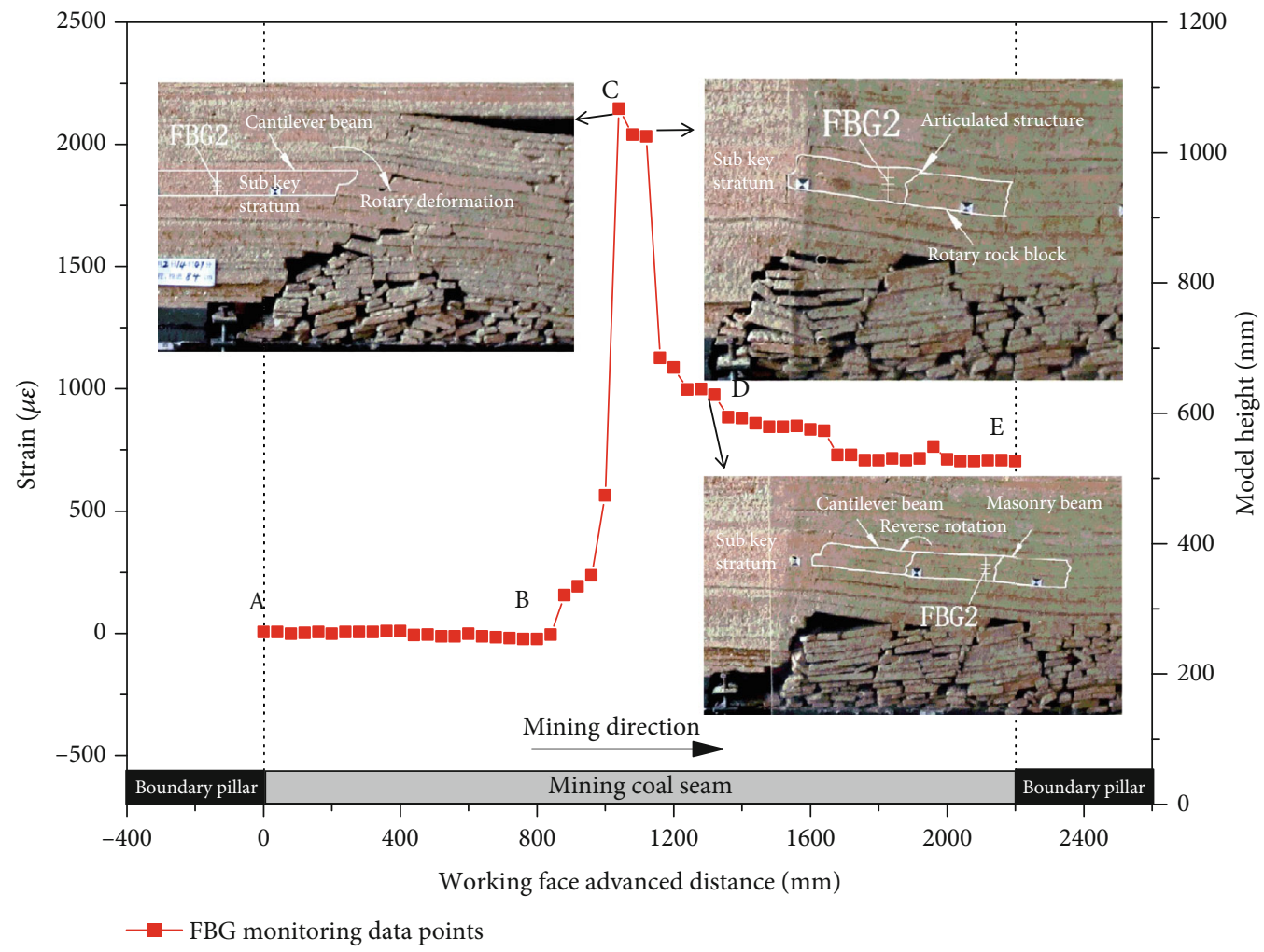

FIGURE 9: Strain monitoring curve of the subcritical stratum (FBG2). 


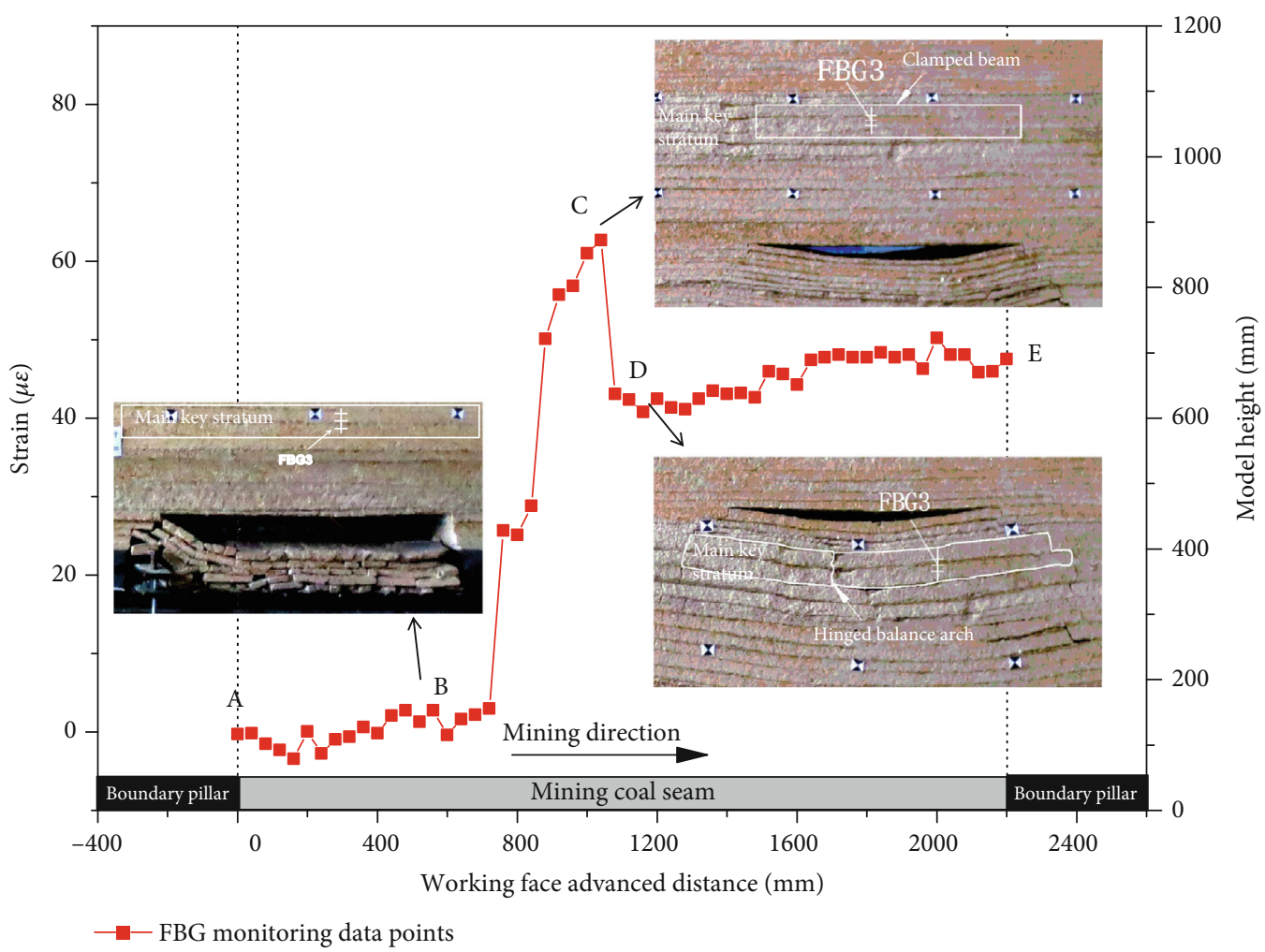

FIGURE 10: Strain monitoring curve of the main key stratum (FBG3).

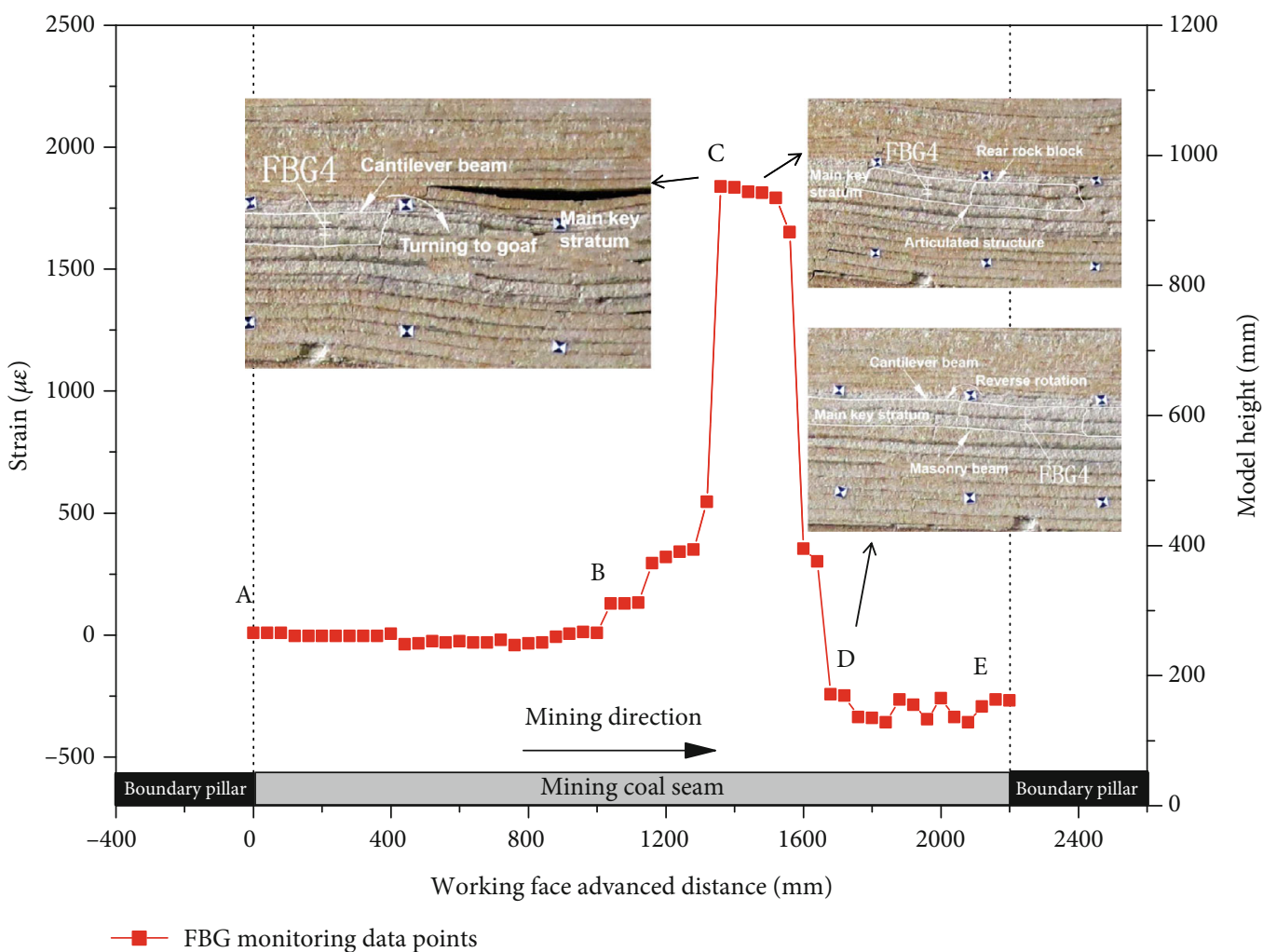

FIGURE 11: Strain monitoring curve of the main key stratum (FBG4). 


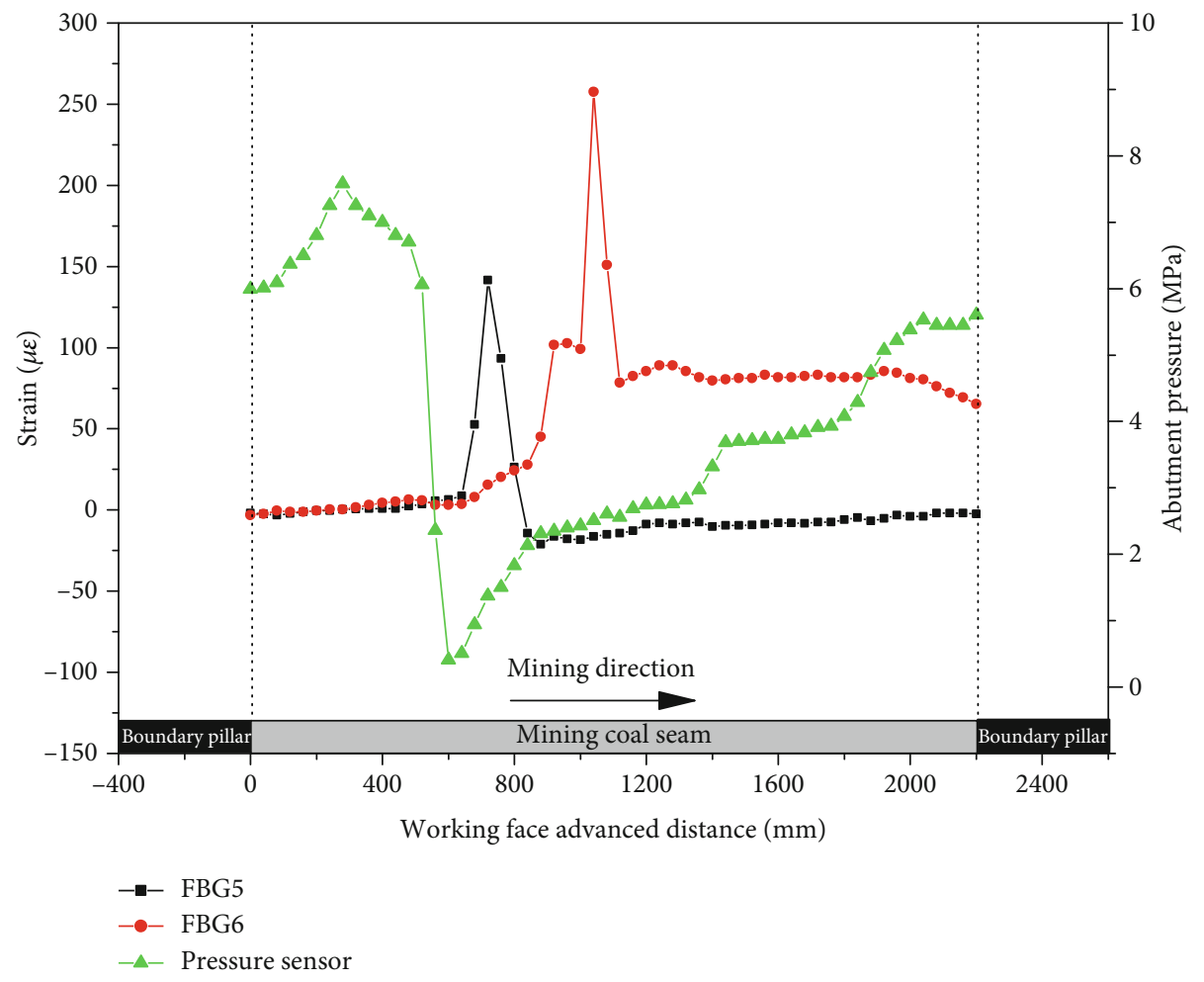

FIgURE 12: Comparison curve between the FBG sensor strain value and the supporting pressure value (FBG5 and FBG6).

overburden load, the strain value of the FBG4 sensor increased sharply to $1838.48 \mu \varepsilon$. When the fully mechanized mining face continued to advance to $1680 \mathrm{~mm}$ (point D in Figure 11), the main key stratum where the FBG4 sensor was located reached the bearing limit and periodic breakage occurred. At this time, the strain value of the FBG4 sensor decreased sharply to $-243.75 \mu \varepsilon$. When the fully mechanized working face continued to advance to $2200 \mathrm{~mm}$ (point $\mathrm{E}$ in Figure 11), the rotation deformation of the main key stratum was limited due to the space limitation of the rotation deformation of the goaf, and the strain value of the FBG4 sensor basically tended to be stable. It was shown that the strain value curve of the FBG4 sensor reflected that the periodic rupture of the main key stratum had a time-continuous process, but the lag phenomenon of the deformation process of the subkey layer was more obvious.

Through the monitoring of the primary and periodic breakage of the main key stratum and the subcritical stratum by the FBG sensor, the results showed that the strain curve of the FBG sensor in the first breaking process of the key layer was a peak, and the strain value basically tended to be stable after the first breaking. The strain curve of the FBG sensor in the periodic breaking process of the key stratum was a plateau, and the periodic breaking process was that the strain value decreased slowly after reaching the peak, mainly because the reverse rotation occurred after the periodic breaking of the key stratum, and the reverse rotation time of the main key stratum was longer than that of the subcritical stratum.

6.2. The Distribution Law of Mining Supporting Pressure Monitored by the FBG Sensor. It shows the one-to-one corre- spondence curve diagram between the strain value of overburden deformation monitored by the FBG5 and FBG6 sensors and the supporting pressure value of the working face floor monitored by the pressure sensor in Figure 12. When the fully mechanized mining face is advanced from $0 \mathrm{~mm}$ to $400 \mathrm{~mm}$, the supporting pressure value of the working face is basically above the original rock stress value due to the action of the front side exceeding the front supporting pressure, but the strain value monitored by the FBG5 and FBG6 sensors was still $0 \mu \varepsilon$ at this time. When the working surface advanced to $480 \mathrm{~mm}$, the first pressure on the working surface occurred, and a significant stress concentration phenomenon appeared in front of the working surface. The peak value of the support pressure reached $6.35 \mathrm{MPa}$. At this time, the strain values of the FBG5 and FBG6 sensors began to change obviously. When the working face continued to move forward, the supporting pressure began to decrease gradually, the minimum value was $0.45 \mathrm{MPa}$, and it showed a trough state. At this time, the strain values of the FBG5 and FBG6 sensors began to increase gradually. As the working face continued to move forward, the supporting pressure value gradually increased until the end of mining, and the pressure value increased to $5.83 \mathrm{MPa}$. When the working face advanced to $700 \mathrm{~mm}$, the strain peak of the FBG5 sensor appeared to be $142.48 \mu \varepsilon$. When the working face advanced to $1080 \mathrm{~mm}$, the peak strain of the FBG6 sensor was $273.85 \mu \varepsilon$. Then, the working surface continues to be mined until the end of mining, and the strain values of the FBG5 and FBG6 sensors gradually decrease.

It shows the one-to-one correspondence curve diagram between the strain value of overburden deformation 


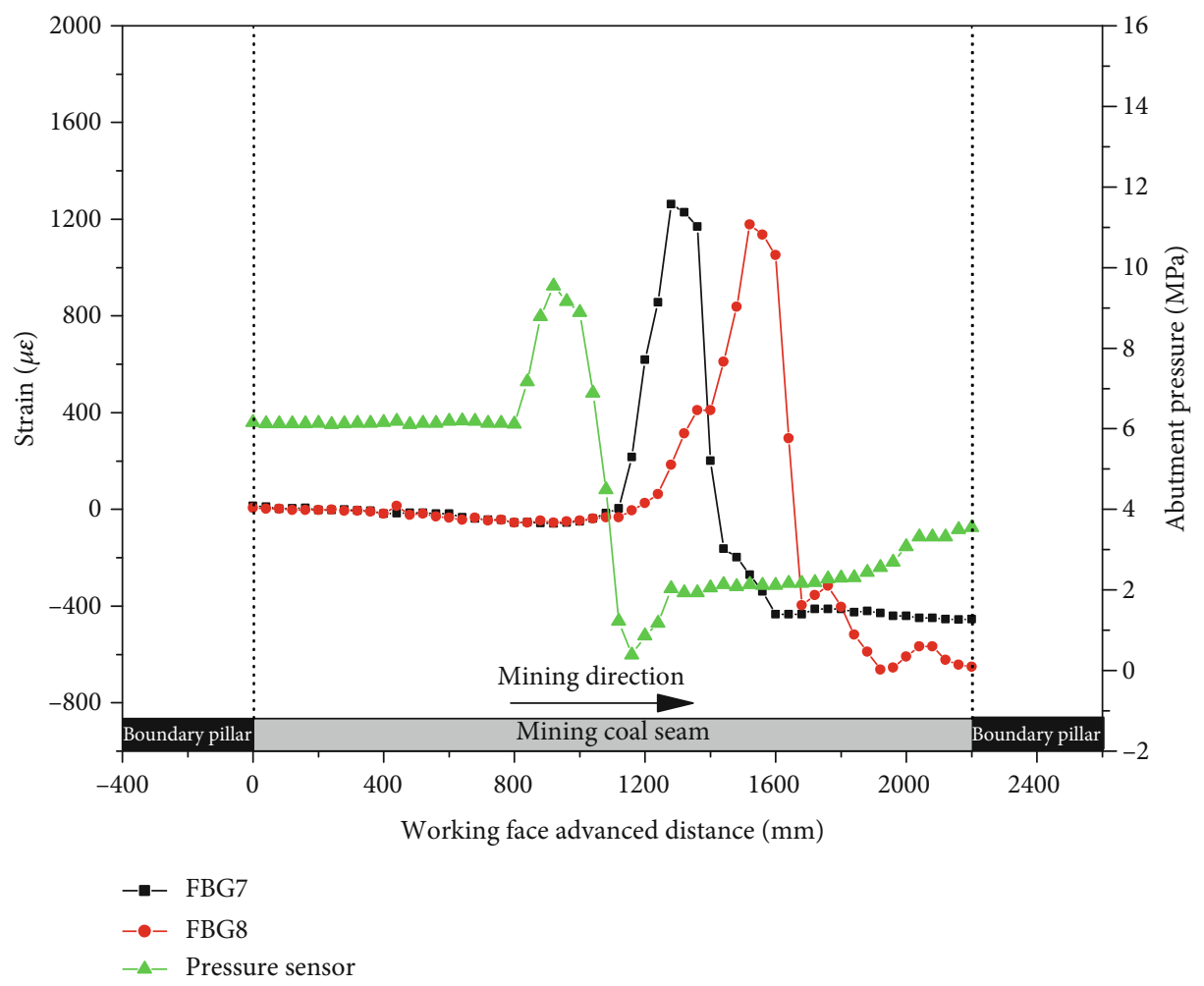

FIGURE 13: Comparison curve between the FBG sensor strain value and the supporting pressure value (FBG7 and FBG8).

monitored by the FBG7 and FBG8 sensors and the supporting pressure value of the working face floor monitored by the pressure sensor in Figure 13. When the fully mechanized working face advanced from the cut hole to $1040 \mathrm{~mm}$, the supporting pressure was basically above the original rock stress value. The stress peak value of the supporting pressure is $9.12 \mathrm{MPa}$ when the fully mechanized mining face advanced to $840 \mathrm{~mm}$, because the mining had not disturbed the overburden position of the FBG sensor, and the strain values of FBG7 and FBG8 are basically unchanged in this time. When the fully mechanized mining face continued to advance to $1120 \mathrm{~mm}$, the minimum supporting pressure was reduced to $0.35 \mathrm{MPa}$, and the strain values of the FBG7 and FBG8 sensors began to increase sharply. When the working surface advanced to $1240 \mathrm{~mm}$, the strain peak value of the FBG7 sensor is $1326.43 \mu \varepsilon$. When the working surface advanced to $1520 \mathrm{~mm}$, the strain peak value of the FBG8 sensor is $1295.32 \mu \varepsilon$. When the working face continued to advance until the end of coal mining, the supporting pressure began to increase gradually, but the pressure value increased slightly and was basically in a stable state in the later stage. At the same time, the strain values of the FBG7 and FBG8 sensors began to decrease sharply, but they were also basically in a stable state in the later stage.

The results show that there is a peak stage and a trough stage for the floor supporting pressure value and the strain value of the FBG sensor in the mining process of the fully mechanized coal face, respectively. From the analysis of mine pressure and stratum control, coal seam mining makes the load of the overlying rock mass transfer to both sides of the strike direction of the working face. As a result, the peak stage of the supporting pressure of the working face is located in a certain range of coal and rock mass in front of the working face. At this time, the strain value of the FBG sensor begins to increase in a negative direction, indicating that the FBG sensor is in a state of increasing pressure stress. After the working face is advanced for a certain distance, the supporting pressure value decreases sharply, and its trough stage is located in the goaf behind the working face. With the collapse of the goaf and the accumulation of rock blocks, the supporting pressure value increases to a certain extent, but the increased range is not significant. At the same time, the collapse of rock will lead to the increase of the strain value of the FBG sensor, and the strain reaches the peak value when the collapse of rock is broken. Therefore, the decreasing stage of the strain value of the FBG sensor indicates the leading bearing pressure increasing stage in the working face, and the peak stage represents the collapse process of overburden and the stage where the supporting pressure decreases first and then increases. This is also the stage where the support pressure gradually recovers after the rock mass in the goaf is gradually compacted.

\section{Conclusion}

(1) Aiming at the mechanical transfer interface effect between the strain transfer of the FBG sensor and packaging material and the matrix deformation in the physical similarity model test, a hypothetical condition for strain transfer of fiber Bragg grating sensors suitable for physical models is proposed in the article. Establishing a strain transfer model which 
considers the half-length of the sensor and the elastic modulus and Poisson's ratio of similar material can improve the monitoring accuracy of fiber Bragg grating sensors in the model test

(2) The strain curve of the FBG sensor has a good oneto-one correspondence with the movement of key strata in the overburden. When the key stratum is broken for the first time, the strain curve of the FBG sensor shows a peak shape. When the key stratum is broken periodically, the key stratum deforms in a bidirectional rotating motion in the state of the cantilever beam. At this time, the strain curve of the FBG sensor is plateau-shaped and will last for a period of time

(3) The strain curve of the FBG sensor has a good corresponding relationship with the change of supporting pressure. The strain curve reflects the collapse shape of rock strata and the alternating process of tensile and compressive stress in the process of movement. When the coal seam is fully mined, the strain curve of the FBG sensor is in the trough shape, and the supporting pressure curve is in the convex peak shape. The test results show that the supporting pressure value of the working face will increase with the increase of the buried height of the sensor, and the horizontal dislocation will occur. There is a linear relationship between the supporting pressure and the strain value in the range of the influence of the advance bearing pressure; that is to say, the change of the supporting pressure of the overburden can be partially reflected by the FBG sensor

\section{Data Availability}

I declare that all the data in this article are original by the author, and all the data are true and reliable. The data used to support the findings of this study are included within the article. All data, models, and code generated or used during the study appear in the submitted article. I promise that the data of the research results of this paper can be open and shared.

\section{Disclosure}

I would like to declare on behalf of my co-authors that the work described was an original research that has not been published previously and not under consideration for publication elsewhere, in whole or in part.

\section{Conflicts of Interest}

No conflict of interest exits in the submission of this manuscript.

\section{Authors' Contributions}

Lei Wulin and Chai Jing are co-first authors. The manuscript is approved by all authors for publication.

\section{Acknowledgments}

This study is supported by the National Natural Science Foundation of China (Nos. 51174280 and 51804244) and the Doctoral Scientific Fund Project of Chinese Ministry of Education (No. 20126121110003). The authors would also like to thank Dr. Zhang and Dr. Du for participating in the model test and for valuable comments and suggestions on the improvement of the manuscript. Otherwise, this study would not have a smooth implementation without them.

\section{References}

[1] Q. Minggao and J. Xu, "Behaviors of strata movement in coal mining," Journal of China Coal Society, vol. 44, no. 4, pp. 973-984, 2019.

[2] Q. Sun, J. Zhang, Q. Zhang, and X. Zhao, "Analysis and prevention of geo-environmental hazards with high-intensive coal mining: a case study in China's western eco-environment frangible area," Energies, vol. 10, no. 6, p. 786, 2017.

[3] P. Zhao, R. Zhuo, S. Li, C.-H. Ho, H. Lin, and H. Liu, "Research on the effect of coal seam inclination on gas migration channels at fully mechanized coal mining face," Arabian Journal of Geosciences, vol. 12, no. 18, p. 597, 2019.

[4] Q. Huang, Y. He, and J. Cao, "Experimental investigation on crack development characteristics in shallow coal seam mining in China," Energies, vol. 12, no. 7, p. 1302, 2019.

[5] G. Wang, P. Yihui, and R. Huaiwei, "Intelligent coal mining pattern and technological path," Journal of Mining And Strata Control Engineering, vol. 1, pp. 6-20, 2020.

[6] C. Piao, S. Lei, J. Yang, and L. Sang, "Experimental Study on the Movement and Evolution of Overburden Strata Under Reamer-Pillar Coal Mining Based on Distributed Optical Fiber Monitoring," Energies, vol. 12, no. 1, p. 77, 2019.

[7] P. Zhao, S. Li, C.-H. Ho, H. Lin, and R. Zhuo, "Crack propagation and material characteristics of rocklike specimens subject to different loading rates," Journal of Materials in Civil Engineering, vol. 31, no. 7, article 04019113, 2019.

[8] S. H. Tang, Y. Pan, Y. H. Huang, and X. W. Ji, “Application research of micro-seismic monitoring technology to geostress hazards in deep mining," Chinese Journal of Rock Mechanics and Engineering, vol. 28, Supplement 2, pp. 3597-3603, 2009.

[9] L. Yanbiao, Y. Libo, and T. Qian, "The 40 years of optical fiber sensors in China," Acta Optica Sinica, vol. 38, no. 3, article 0328001, 2018.

[10] D. Kinet, P. Mégret, K. Goossen, L. Qiu, D. Heider, and C. Caucheteur, "Fiber Bragg grating sensors toward structural health monitoring in composite materials: challenges and solutions," Sensors, vol. 14, no. 4, pp. 7394-7419, 2014.

[11] D. S. Raffaella, "Fibre optic sensors for structural health monitoring of aircraft composite structures: recent advances and applications," Sensors, vol. 15, no. 8, pp. 18666-18713, 2015.

[12] A. Mendez, T. F. Morse, and F. Mendez, "Applications of embedded optical fiber sensors in reinforced concrete buildings and structures," in Proceedings of SPIE-The International Society for Optical Engineering, Beijing China, 1990.

[13] J. D. Prohaska, E. Snitzer, B. Chen, M. H. Maher, E. G. Nawy, and W. W. Morey, "Fiber optic Bragg grating strain sensor in large-scale concrete structures," in Fiber optic smart structures and skins V International Society for Optics and Photonics, Boston, USA, 1993. 
[14] V. Slowik, E. Schlattner, and T. Klink, "Fiber Bragg grating sensors in concrete technology," Laser, vol. 3, pp. 109-119, 1998.

[15] F. Ansari, "Real-time condition monitoring of concrete structures by embedded optical fibers, in nondestructive testing of concrete elements and structure," in Proceedings of the ASCE, pp. 49-59, San Antonio, 1992.

[16] W. L. Schulz, J. P. Conte, E. Udd, and J. M. Seim, "Static and dynamic testing of bridges and highways using long-gage fiber Bragg grating based strain sensors," in Spie 7-th International Symposium on Smart Structures \& Materials, pp. 79-86, California, USA, 2000.

[17] Y. Wang, C. S. Tjin, J. Hao et al., "Determination of load-strain characteristics of concrete slabs by using embedded fiber Bragg grating sensors," in Proceedings of SPIE-The International Society for Optical Engineering, pp. 297-304, San Diego, USA, 2000.

[18] M. J. Yeager, M. D. Todd, and C. T. Key, "Structural health monitoring of composite structures with embedded fiber Bragg gratings," in Proceedings of 5th International Forum on Optoelectronic Sensor-based Monitoring in Geo-engineering, pp. 20-28, Nanjing: Nanjing University, 2014.

[19] L. I. Hong, L. I. Dong, and Z. Bai, "Progress in study and application of smart health monitoring method by fiber optic sensor in civil engineering," Earthquake Engineering and Engineering Vibration, vol. 22, no. 6, pp. 76-83, 2002.

[20] J. Desheng, "Study on application of FBG sensor for structure reinforcement monitoring," China Civil Engineering Journal, vol. 37, no. 5, pp. 50-53, 2004.

[21] R. Y. Jiang, W. U. Min, R. Z. Ling, and Y. U. Yu, "A fiber-optic intrusion alarm system based on quasi-distributed FBG sensors," Chinese Journal of Sensors and Actuators, vol. 20, no. 5, pp. 998-1002, 2007.

[22] J. H. Dong, H. P. Xie, L. Zhang et al., "Application of optical fiber grating sensor in gravity dam structure model test," Journal of Sichuan University, vol. 41, pp. 41-46, 2009.

[23] Z. Zhou, J. He, and J. P. Ou, "Measurement technique based on the FBG-BOTDA (R) for infrastructures," Tumu Gongcheng Xuebao/China Civil Engineering Journal, vol. 43, no. 3, pp. 111-118, 2010.

[24] H. Zhu, J. Yin, W. Jin, and T. M. K. Kuo, "Health monitoring of foundations using fiber Bragg grating sensing technology," China Civil Engineering Journal, vol. 43, no. 6, pp. 109-115, 2010.

[25] W. Guangqing, S. Bin, S. Hu, K. Li, and J. H. Yin, "Several key problems in tunnel construction monitoring with FBG," Chinese Journal of Geotechnical Engineering, vol. 31, no. 4, pp. 571-576, 2009.

[26] W. Jing, L. Shucai, S. Bin et al., "Trifarious FBG sensor strain transfer characteristics and its application to tunnel excavation model test," Journal of Engineering Geology, vol. 21, no. 2, pp. 182-189, 2013.

[27] Y. Q. Ni, J. Wang, Q. L. Xie, and K. C. Lam, “A fiber Bragg grating sensing network for structural integrity monitoring of underground water pipes: analysis of monitoring data," in Proceedings of 5th International Forum on Opto-electronic Sensorbased Monitoring in Geo-engineering, pp. 34-41, Nanjing: Nanjing University, 2014.

[28] Q. Liu, Z. He, and T. Tokunaga, "Sensing the earth crustal deformation with nano-strain resolution fiber-optic sensors," Optics Express, vol. 23, no. 11, pp. A428-A436, 2015.
[29] M. Liang, X. Fang, G. Wu, N. Chen, Y. Ning, and C. Gu, “A hydraulic fiber Bragg grating force sensor and its monitoring system for axial bolt load measurement in anchorage engineering," Measurement Science and Technology, vol. 29, no. 12, p. $125105,2018$.

[30] M. Liang and X. Fang, "Application of fiber Bragg grating sensing technology for bolt force status monitoring in roadways," Applied Sciences, vol. 8, no. 1, p. 107, 2018.

[31] M. Liang, X. Fang, G. Wu, G.-z. Xue, and H.-w. Li, “A Fiber Bragg grating pressure sensor with temperature compensation based on diaphragm-cantilever structure," Optik, vol. 145, pp. 503-512, 2017.

[32] J. Chai, Q. Liu, J. Liu, and D. Zhang, "Optical fiber sensors based on novel polyimide for humidity monitoring of building materials," Optical Fiber Technology, vol. 41, pp. 40-47, 2018.

[33] J. Chai, W. Du, Q. Yuan, and D. Zhang, “Analysis of test method for physical model test of mining based on optical fiber sensing technology detection," Optical Fiber Technology, vol. 48, pp. 84-94, 2019.

[34] J. Chai, W. Lei, W. Du et al., "Experimental study on distributed optical fiber sensing monitoring for ground surface deformation in extra-thick coal seam mining under ultra-thick conglomerate," Optical Fiber Technology, vol. 53, p. 102006, 2019.

[35] Q. Yuan, J. Chai, D. Zhang, J. Liu, Y. Li, and G. Yin, “Monitoring and characterization of mining-induced overburden deformation in physical modeling with distributed optical fiber sensing technology," Journal of Lightwave Technology, vol. 38, no. 4, pp. 881-888, 2020.

[36] P. Roriz, L. Carvalho, O. Frazão, J. L. Santos, and J. A. Simões, "From conventional sensors to fibre optic sensors for strain and force measurements in biomechanics applications: a review," Journal of Biomechanics, vol. 47, no. 6, pp. 12511261, 2014.

[37] M. Pospíšilová, G. Kuncová, and J. Trögl, "Fiber-optic chemical sensors and fiber-optic bio-sensors," Sensors, vol. 15, no. 10, pp. 25208-25259, 2015.

[38] L. Dziuda, "Fiber-optic sensors for monitoring patient physiological parameters: a review of applicable technologies and relevance to use during magnetic resonance imaging procedures," Journal of Biomedical Optics, vol. 20, no. 1, article 010901, 2015.

[39] C. Jing, Z. Ding-Ding, and L. I. Yi, "Research progress of optical fiber sensing technology in geotechnical and geological engineering," Journal of Architecture and Civil Engineering, vol. 32, no. 3, pp. 28-37, 2015.

[40] C. Jing, Y. Qiang, L. I. Yi, W. A. N. G. Shuai, and S. U. N. Yayun, "Application analysis on method of physical model test with optical fiber sensing technique," Journal of Engineering Geology, vol. 23, no. 6, pp. 1100-1108, 2015.

[41] K. O. Hill, Y. Fujii, D. C. Johnson, and B. S. Kawasaki, "Photosensitivity in optical fiber waveguides: application to reflection filter fabrication," Applied Physics Letters, vol. 32, no. 10, pp. 647-649, 1978.

[42] E. J. Friebele, "Fiber Bragg grating strain sensors: present and future applications in smart structures," Optics and Photonics News, vol. 9, no. 8, pp. 33-37, 1998.

[43] R. Broennimann, P. M. Nellen, P. Anderegg, and U. J. Sennhauser, "Application of optical fiber sensors on the power dam of Luzzone," in Proceedings of SPIE, vol. 3407, pp. 386391, Beijing China, 1998. 
[44] G. Meltz, W. W. Morey, and W. H. Glenn, "Formation of Bragg gratings in optical fibers by a transverse holographic method," Optics Letters, vol. 14, no. 15, pp. 823-825, 1989.

[45] A. Li and G. Zhou, "Progress and prospect of fiber Bragg grating sensors measurement technology (I): strain and temperature measurement," Dongnan Daxue Xuebao (Ziran Kexue Ban)/Journal of Southeast University, vol. 39, no. 6, pp. 12981306, 2009.

[46] Z. Weigang, K. Guiyun, and D. Xiaoyi, "Theoretical and experimental study of fiber grating multi-point sensing," Acta Optica Sinica, vol. 24, no. 3, pp. 330-336, 2004.

[47] M. Liang, Intelligent sensing theory and key technologies of multi-parameter fiber bragg grating in coal mining, China University of Mining and Technology, 2019.

[48] D. Zhang, J. Chai, Y. Li, Y. Sun, X. Liu, and G. Zhang, "Strain transfer function of embedded fiber Bragg grating sensors for unconsolidated layer settlement deformation detector and its application," Chinese Journal of Rock Mechanics \& Engineering, vol. 34, pp. 3289-3297, 2015.

[49] D.-S. Li, L. R. Hongnan Li Sr., and G. Song, "Strain transferring analysis of fiber Bragg grating sensors," Optical Engineering, vol. 45, no. 2, article 024402, 2006. 